\title{
Avaliação da Degradação Térmica e Fotooxidativa do ABS Automotivo
}

\author{
Elisabete M. S. Sanchez, Márcia M. C. Ferreira e Maria Isabel Felisberti
}

Resumo: A degradação do ABS foi avaliada após envelhecimento térmico (ASTM D794) e fotooxidativo (ASTM G53 e G24). Essas condições foram escolhidas na tentativa de simular as condições a que esse polímero é submetido durante seu ciclo de vida como componente automobilístico. As mudanças ocorridas no ABS envelhecido pelos três métodos, em diferentes tempos, foram caracterizadas por ensaios mecânicos de tração e impacto, pelo índice de fluidez, pelo índice de carbonilas (FT-IR), pelo índice de amarelecimento e por fotografias ampliadas das fraturas de impacto. Os resultados mostraram que cada técnica utilizada fornece uma resposta característica em função do método de envelhecimento utilizado. A aplicação de técnicas de análise multivariada aos resultados permitiu uma visualização da degradação do material em função das técnicas de envelhecimento.

Palavras-chave: ABS, degradação térmica e fotooxidativa, propriedades, reciclagem pós consumo.

\section{Introdução}

O terpolímero poli(acrilonitrila-butadienoestireno), ABS, é um dos materiais mais utilizados pela indústria automobilística. O seu mecanismo de degradação, tanto térmico como fotooxidativo, tem sido bastante estudado. Entretanto, pouco se conhece da influência da extensão da degradação sobre as propriedades do ABS.

A maioria dos veículos no Brasil é submetida diariamente a condições extremas de radiação e calor em função do clima tropical. A temperatura interna de um automóvel exposto ao sol pode chegar a $80^{\circ} \mathrm{C}$. Esse efeito, combinado com a radiação ultravioleta, é facilmente observado em painéis degradados de automóveis com alguns anos.

Os polímeros ABS são constituídos de uma fase elastomérica dispersa em uma matriz vítrea, exi- bindo excelente tenacidade e boa estabilidade dimensional. O componente elastomérico, geralmente o polibutadieno ou um copolímero de butadieno, forma uma discreta fase dispersa no componente termoplástico, um copolímero de estireno e acrilonitrila (SAN).

O ABS automotivo é utilizado em painéis de instrumentos, suportes de lâmpadas, revestimentos de colunas e outras guarnições internas. Essas aplicações requerem um material de alto fluxo, boa estabilidade no processamento e temperatura de distorção na faixa de $80-110^{\circ} \mathrm{C}$. Também é muito utilizado em partes niqueladas com excelente adesão, onde as aplicações típicas são maçanetas, suportes de espelhos, grades e guarnições decorativas (Kulich et al., 1996).

A radiação ultravioleta é um dos fatores mais efetivos para a degradação de materiais orgânicos 
através de fotooxidação. Esse é um fator decisivo com respeito ao tempo de vida de polímeros que são expostos ao tempo. A radiação ultravioleta causa modificações químicas irreversíveis que afetam as propriedades mecânicas de materiais orgânicos. Essa degradação pode tornar os materiais quebradiços com perda de resistência e mudança de cor (Berre e Lala, 1989).

Carter e McCallum (1994) avaliaram, por espectroscopia de infravermelho fotoacústica, amostras de ABS na forma de placas moldadas, em quatro diferentes tipos de ensaios de envelhecimento acelerado, tentando simular o interior de um automóvel. A exposição por cinco dias em dispositivo com lâmpada arco-xenônio foi aproximadamente igual a doze meses na Flórida. O processo de degradação resultou na formação de uma camada superior quebradiça. Os autores concluíram que a oxidação fotoquímica foi a causa da degradação e não o calor. Adeniyi (1984), através do estudo da degradação térmica e fotooxidativa do ABS, sugere um mecanismo de degradação para o polibutadieno (PB). As reações de degradação do PB são controladas pela reatividade dos três isômeros: 1,2-vinila; 1,4-cis e 1,4-trans. A degradação do ABS tem início com a formação de hidroperóxidos induzida pela formação de radicais. A subsequente degradação é propagada pela decomposição dos hidroperóxidos os quais induzem reações em cadeia. Os três isômeros do PB degradam por mecanismos semelhantes, no entanto, o 1,2-vinila apresenta maior facilidade de formação de radicais devido ao hidrogênio lábil localizado em um carbono terciário. A iniciação envolve a abstração do hidrogênio resultando em um radical alquila, o qual se combina com o oxigênio para produzir um radical peróxido de alquila. A abstração do último hidrogênio leva à produção de um hidroperóxido de alquila. Os hidroperóxidos se decompõem em radicais livres que tornam o polímero sensível à fotodegradação. Os peróxidos presentes no primeiro estágio são fotoquimicamente instáveis e se decompõem em radicais alcóxidos, que são finalmente convertidos em carbonilas insaturadas e saturadas. No segundo estágio são formadas estruturas reticuladas carbono-carbono. Essas estruturas são mais estáveis fotoquimicamente e são responsáveis pela insolubilidade de amostras de ABS degradadas. A perda das propriedades elastoméricas está associ- ada princilpalmente com a perda de insaturação do PB. Em condições mais severas de envelhecimento verifica-se a reticulação e quebra catastrófica da matriz por meio da cisão do PS-PB.

Gardette et al. (1995) apresentam uma revisão sobre os mecanismos de fotooxidação dos polímeros estirênicos, incluindo o poliestireno (PS), SAN e ABS, por espectroscopia de infravermelho. Os filmes desses polímeros foram submetidos à radiação em comprimentos de onda na faixa de 300 a $253,7 \mathrm{~nm} 60^{\circ} \mathrm{C}$. Para os filmes de ABS submetidos à radiação à $300 \mathrm{~nm}$ na presença de oxigênio a $60^{\circ} \mathrm{C}$, modificações importantes foram verificadas no espectro de infravermelho. Na região de absorção de hidroxilas apareceu um banda larga com um máximo a $3460 \mathrm{~cm}^{-1}$. Na região de absorção de carbonilas apareceu uma banda larga com máximos a 1718 e $1722 \mathrm{~cm}^{-1}$ e um ombro a $1785 \mathrm{~cm}^{-1}$.

\section{Experimental}

O ABS utilizado foi o Cycolac GMP 5600, natural, gentilmente cedido pela GE Plastics South America, na forma de corpos de prova de tração (ASTM D638) e de impacto (ASTM D256).

Os métodos de envelhecimento foram: 1) térmico em estufa marca Fanem, a $80^{\circ} \mathrm{C}$ (ASTM 794), 2) fotoquímico segundo a norma ASTM G53, filtrada por vidro, no equipamento C-UV Comexim, dotado de lâmpadas fluorescentes tipo UVB, a 50 $\pm 5^{\circ} \mathrm{C}$ e 3) fotoquímico e térmico em uma caixa preta sem ventilação, recoberta por vidro, construída segundo a norma ASTM G24. Os dados de radiação foram obtidos do CEPAGRI-UNICAMP.

As amostras foram submetidas a tratamento térmico a $90^{\circ} \mathrm{C}$ por $30 \mathrm{~min}$ em atmosfera de argônio para uniformizar a sua história térmica e diminuir as possíveis tensões produzidas na moldagem por injeção, antes do envelhecimento.

As mudanças ocorridas com o envelhecimento foram acompanhadas por ensaios mecânicos de tração, segundo a norma ASTM D638, com célula de carga Trd 24, à velocidade de $10 \mathrm{~mm} / \mathrm{min}$, no equipamento EMIC DL 2000. A resistência ao impacto foi avaliada segundo a norma ASTM D256 (Izod com entalhe), à temperatura ambiente, em um equipamento EMIC. O índice de fluidez foi obtido segundo a norma ASTM D1238 em um plastômetro DSM MI3, a $220^{\circ} \mathrm{C}$ com carga de 
$10 \mathrm{~kg}$. Os espectros na região de infravermelho foram obtidos em um equipamento Nicolet com um acessório de refletância especular. O índice de amarelecimento foi obtido segundo a norma ASTM D1925 em um equipamento MacBeth Color-eye. As fotografias ampliadas foram obtidas com uma lupa Micronal com aumento de sete vezes. A análise multivariada foi realizada com o Programa PIROUETE Multivariate Data Analysis for IBM PS Systems, versão2.1, Infometrix, 1997.

\section{Resultados e Discussão}

Os dados de radiação incidente, referentes ao método ASTM G24, foram obtidos mensalmente. A temperatura no interior da caixa e no ambiente de teste foi medida diariamente entre 12 e $13 \mathrm{~h}$. Na tabela 1 são mostrados os valores médios para cada tempo de envelhecimento a que as amostras foram submetidas.

As figuras 1, 2,3 e 4 comparam os resultados obtidos nos ensaios mecânicos para os três tipos de envelhecimento utilizados, em função do tempo. O envelhecimento térmico realizado segundo a norma ASTM D794 diminuiu a tensão na ruptura nas primeiras horas, seguido de aumento (Figura 1), porém a um nível menor, se comparado com o envelhecimento fotooxidativo. Essa queda inicial pode estar associada a um efeito de annealing que causa relaxamento de tensão nas amostras moldadas por injeção. $\mathrm{O}$ envelhecimento fotooxidativo segundo a norma ASTM G53 causou um aumento gradativo, porém no tempo máximo ensaiado diminuiu. Para o envelhecimento térmico por $2544 \mathrm{~h}$ verificou-se perda total nessa propriedade. Os corpos de prova envelhecidos naturalmente (ASTM G24) sofreram um aumento inicial da tensão na ruptura seguido de gradual diminuição, atingindo valores bem mais altos para tempos correspondentes nos outros dois métodos.

Para o alongamento na ruptura, a perda de propriedade foi observada para os três métodos, sendo muito mais acentuada para os métodos fotooxidativos que para o térmico (Figura 2).

O módulo de elasticidade diminuiu aproximadamente $3 \%$ para as amostras submetidas a $80^{\circ} \mathrm{C}$ e apresentou um máximo em função do tempo de envelhecimento para as amostras submetidas à radiação (Figura 3).

Cada propriedade avaliada através dos ensaios de tração mostrou uma resposta diferente em relação ao tipo de envelhecimento. Em relação à temperatura é mais fácil associar seus efeitos pois toda a massa polimérica sofre a sua ação. Nas amostras submetidas à radiação deve-se levar em conta que os efeitos se iniciam somente na superfície do material e que a degradação tende ocorrer de fora para dentro. Porém, os materiais expostos ao tempo ficaram sujeitos a uma maior variação na radiação e na temperatura.

As amostras envelhecidas termicamente mostram um aumento da resistência ao impacto nas primeiras $48 \mathrm{~h}$, devido provavelmente ao efeito de annealing já mencionado. A diminuição da resistência se deu aproximadamente nos mesmos níveis para as três técnicas, porém para tempos maiores o efeito do envelhecimento térmico se mostrou mais drástico, devido ao efeito da temperatura na massa polimérica.

A figura 5 mostra os resultados obtidos nos ensaios de índice de fluidez. O envelhecimento térmico diminuiu de forma gradativa o índice de fluidez em maior extensão que os outros métodos de envelhecimento. A radiação UV-B (ASTM G53) causou diminuição do índice de fluidez até $72 \mathrm{~h}$, seguida de aumento. Enquanto as amostras envelhecidas naturalmente (ASTM G24) mostraram diminuição do índice de fluidez em função do tempo.

Tabela 1. Dados meteorológicos para o método ASTM G24.

\begin{tabular}{ccccc}
\hline $\begin{array}{c}\text { Tempo de } \\
\text { envelhecimento } \\
\text { (h) }\end{array}$ & Período & $\begin{array}{c}\text { Temperatura média } \\
\text { na caixa } \\
\left({ }^{\circ} \mathbf{C}\right)\end{array}$ & $\begin{array}{c}\text { Temperatura média } \\
\text { ambiente } \\
\left({ }^{\circ} \mathbf{C}\right)\end{array}$ & $\begin{array}{c}\text { Radiação incidente } \\
\text { média } \\
\left(\mathbf{k W} / \mathbf{m}^{2}\right)\end{array}$ \\
\hline 240 & $29 / 11$ a $09 / 12$ & $47 \pm 7$ & $38 \pm 5$ & $23 \pm 7$ \\
480 & $29 / 11$ a $18 / 12$ & $48 \pm 7$ & $39 \pm 4$ & $23 \pm 7$ \\
1176 & $25 / 09$ a $13 / 11$ & $37 \pm 10$ & $29 \pm 5$ & $30 \pm 5$ \\
1860 & $25 / 09$ a $26 / 11$ & $38 \pm 10$ & & $19 \pm 8$ \\
\hline
\end{tabular}




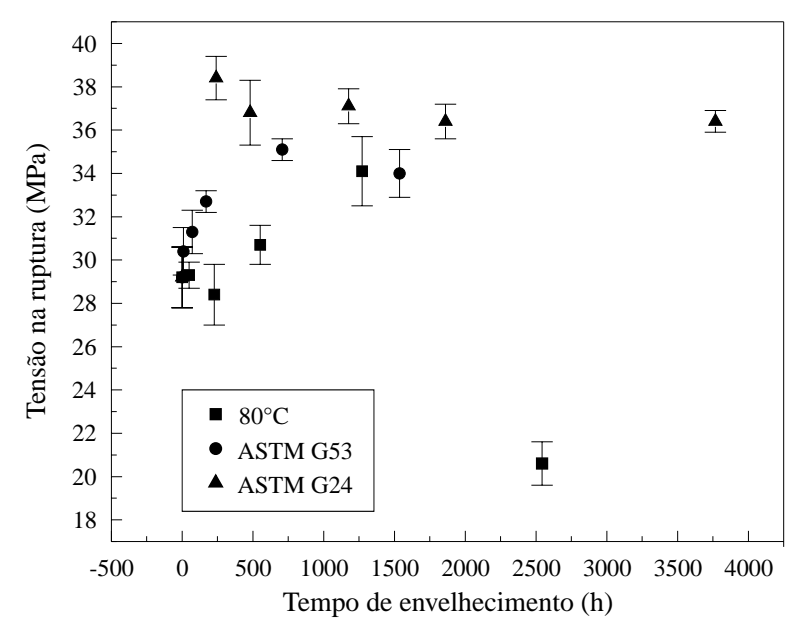

Figura 1. Tensão na ruptura para o ABS em função do tempo de envelhecimento e da técnica utilizada.

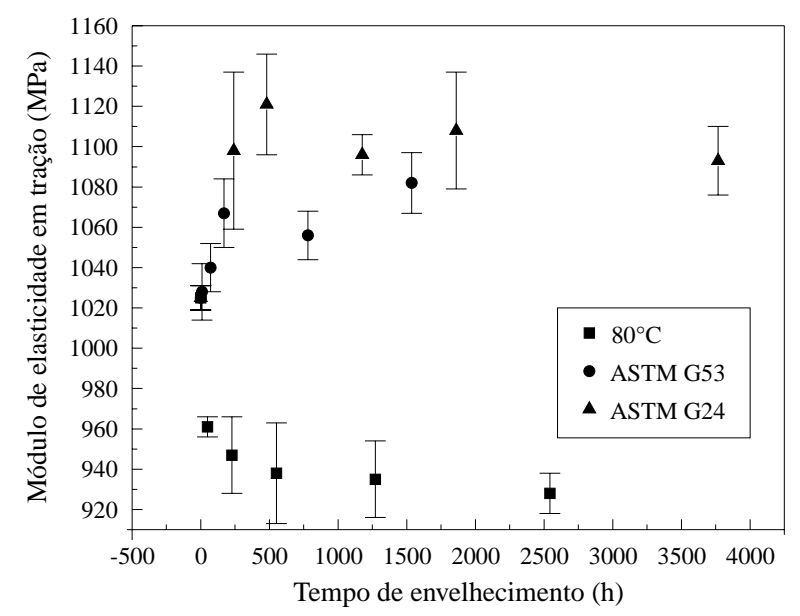

Figura 3. Módulo de elasticidade em tração para o ABS em função do tempo de envelhecimento.

Na figura 6 é mostrada a variação no índice de amarelecimento para o ABS envelhecido pelas três técnicas. Uma amostra de ABS não envelhecida foi utilizada como padrão para as demais. O envelhecimento térmico causou alterações bastante significativas nas amostras de ABS. As amostras submetidas à radiação UV-B foram mais afetadas que as envelhecidas naturalmente.

Os espectros de infravermelho foram obtidos por refletância especular devido ao formato da amostra. Por essa técnica não se tem boa resolução na região de absorção de hidroxilas (4000 a $3000 \mathrm{~cm}^{-1}$ ), assim sendo foram comparadas as regiões de absorção de carbonilas, onde foi possível avaliar as alterações. Foi calculado o índice de carbonila em relação à banda de absorção do $\mathrm{CN}$ a $2236 \mathrm{~cm}^{-1}$, que permaneceu inalterada durante o envelhecimento. Para esse cálculo os espectros

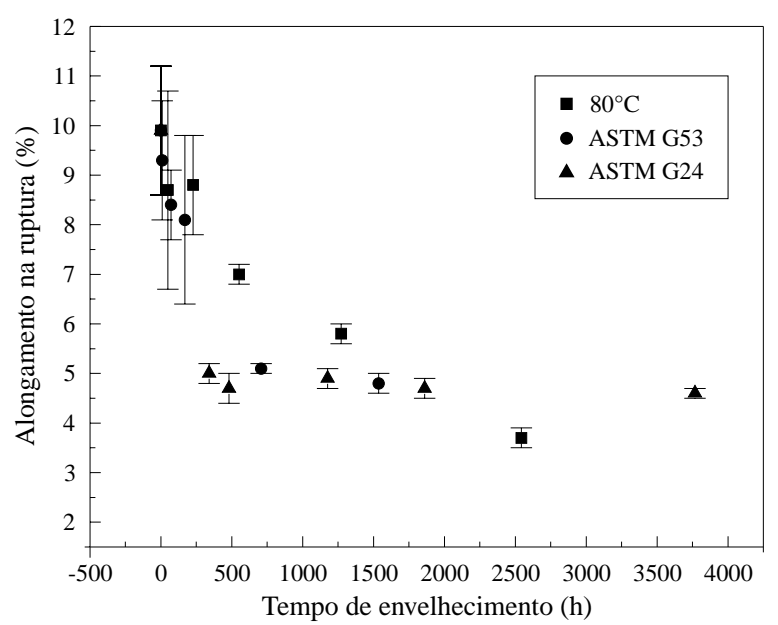

Figura 2. Alongamento na ruptura para o ABS em função do tempo de envelhecimento e da técnica utilizada.

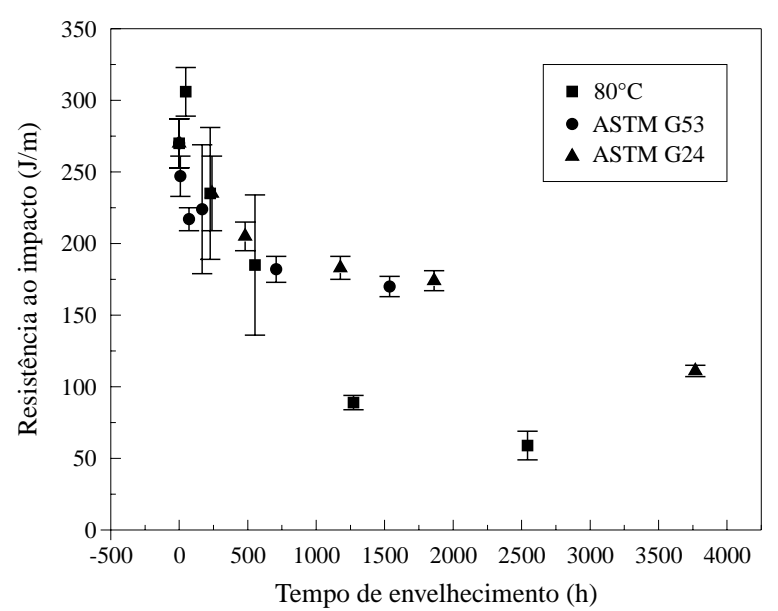

Figura 4. Resistência ao impacto para o $\mathrm{ABS}$ em função do tempo de envelhecimento.

foram expandidos e foi calculada a área sob o pico com auxílio do programa OMNIC 3.1a.

$\mathrm{Na}$ figura 7 são mostrados os espectros para amostras envelhecidas pelas três técnicas em relação ao ABS sem envelhecimento para os tempos onde o índice de carbonila apresentou o máximo valor. Na figura 8 é comparada a variação no índice de carbonila para as três técnicas de envelhecimento (regressão polinomial de segunda ordem).

O aumento dos produtos de degradação na região de $1746 \mathrm{~cm}^{-1}$ alcançaram um máximo em alguns tempos de envelhecimento. Comparando as três técnicas, o envelhecimento térmico a $552 \mathrm{~h}$ foi o que apresentou o maior índice de carbonilas. $\mathrm{O}$ envelhecimento natural forneceu um máximo com $240 \mathrm{~h}$, enquanto que o de radiação UV-B a 168 e $780 \mathrm{~h}$. Verificou-se ainda diminuição nos 


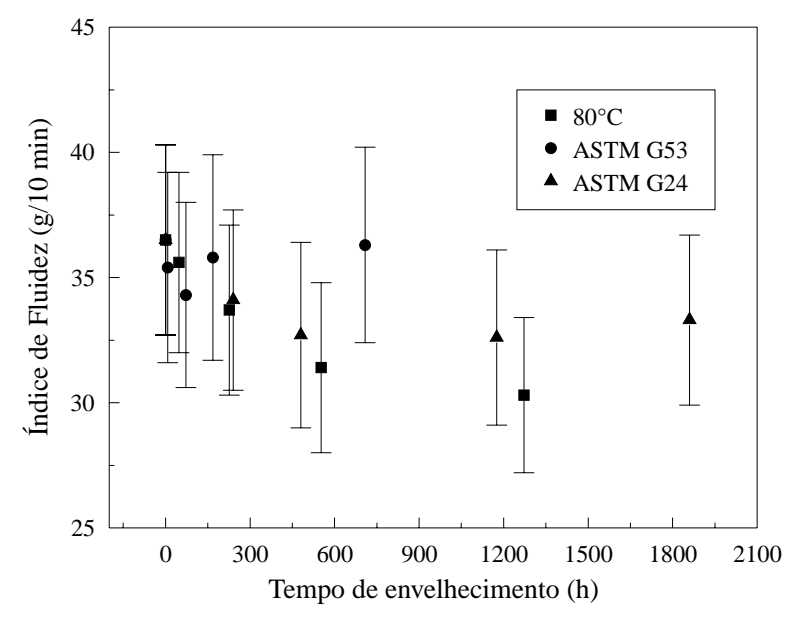

Figura 5. Índice de fluidez para o ABS.

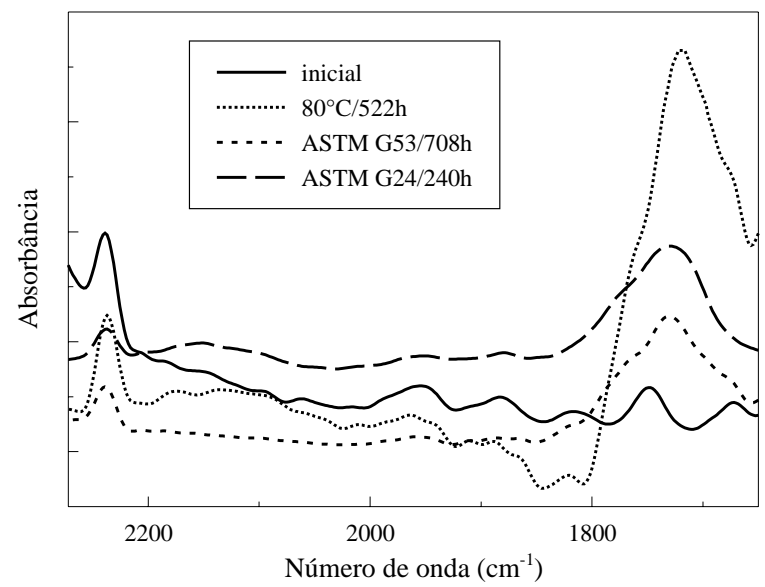

Figura 7. Espectros na região de infravermelho nas regiões de absorção CN $\left(2236 \mathrm{~cm}^{-1}\right)$ e de carbonilas $\left(1746 \mathrm{~cm}^{-1}\right)$.

picos correspondentes às absorções da fase borrachosa a 910,967 e $1640 \mathrm{~cm}^{-1}$.

A análise das fraturas dos corpos de prova, submetidos aos ensaios de impacto, ilustram para as três técnicas, a evolução do envelhecimento na mudança da superfície da fratura de dúctil para frágil. No caso das amostras submetidas à radiação observa-se esse efeito a partir da superfície irradiada (parte superior das amostras). A amostra envelhecida termicamente apresenta uma superfície mais uniforme com uma estria bem definida no centro, ou seja, na parte mais interna do corpo de prova (figura 9).

A análise de componentes principais é uma manipulação matemática da matriz de dados experimentais, cujo objetivo é representar a variação presente nos parâmetros medidos usando um número menor de eixos. Esses novos eixos chamados de fatores ou componentes principais, são combinações lineares das medidas originais

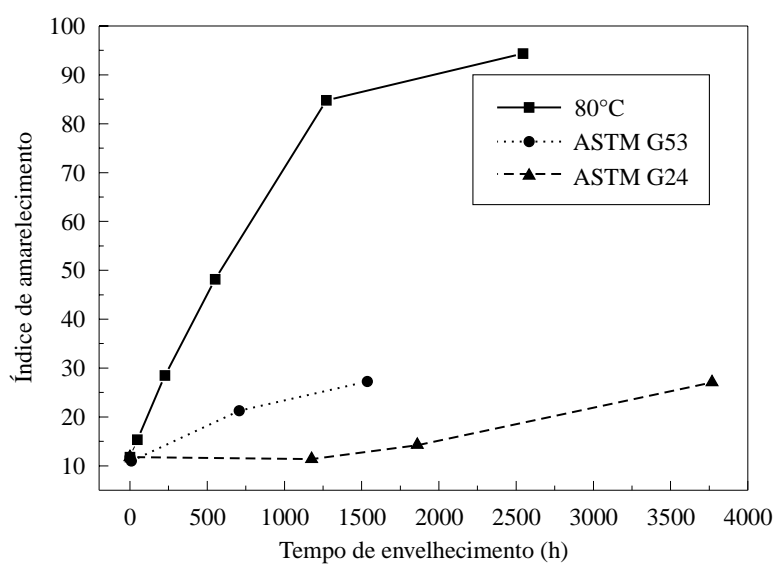

Figura 6. Índice de amarelecimento para o ABS.

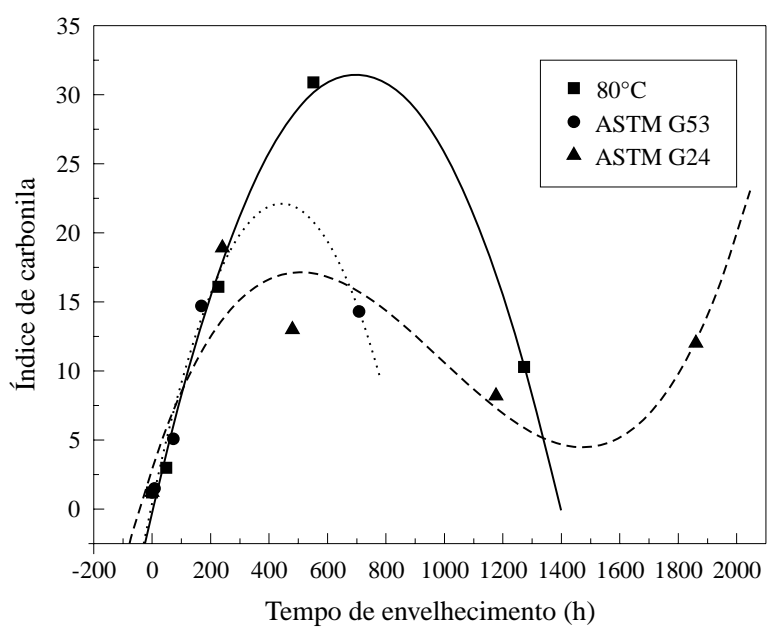

Figura 8. Tendência de variação do índice de carbonila para as três técnicas utilizadas.

e permitem a visualização da natureza multivariada dos dados em um espaço de pequena dimensão, muitas vezes num plano bidimensional. Estes são construídos de maneira a exibir o máximo de informação estatística, isto é, o primeiro fator (PC1) detém a variação máxima dos dados em uma direção. Em outras palavras, esta é a direção que descreve o maior espalhamento das amostras. O segundo fator (PC2) descreve a variância máxima restante e assim por diante. Nesse novo sistema de eixos, o olho humano é capaz de identificar estruturas e tendências nos dados. Gráficos de scores (amostras representadas no sistema de eixos) e de loadings (medida do quanto cada variável original contribui para a obtenção dos fatores) são extremamente úteis para esta visualização (Malinowski, 1991).

Da análise multivariada do ABS, em relação ao tempo de envelhecimento em cada método, 


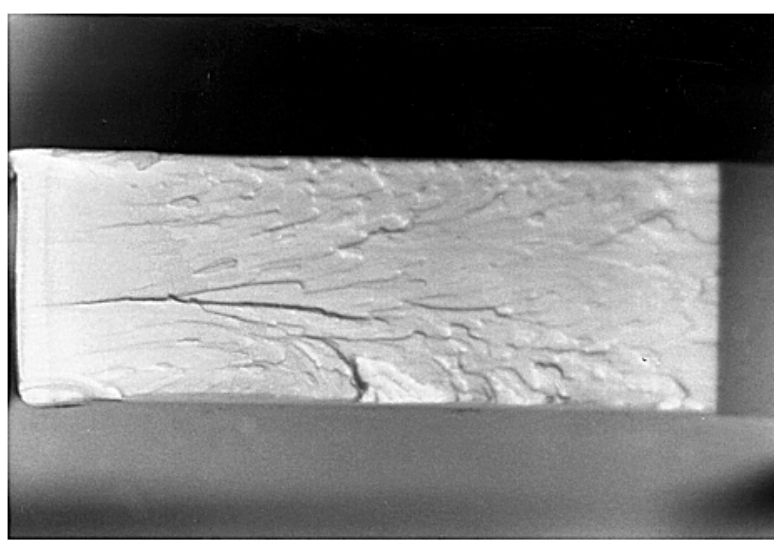

inicial

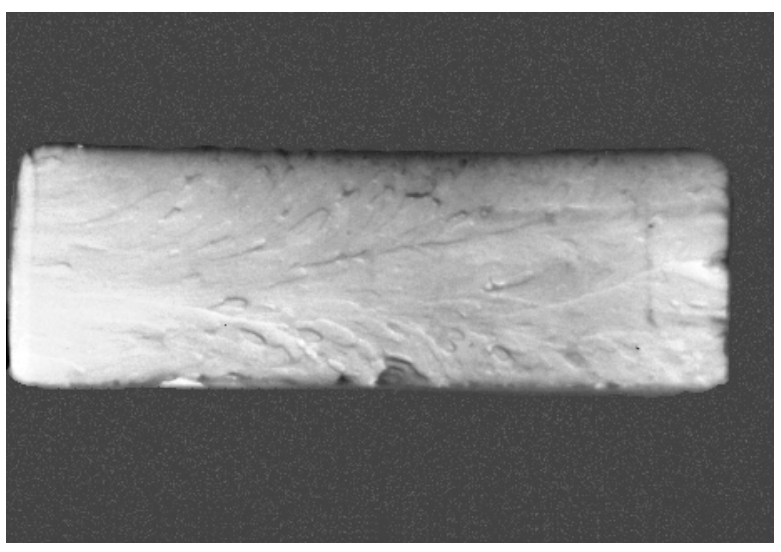

ASTM G53 / 708 h

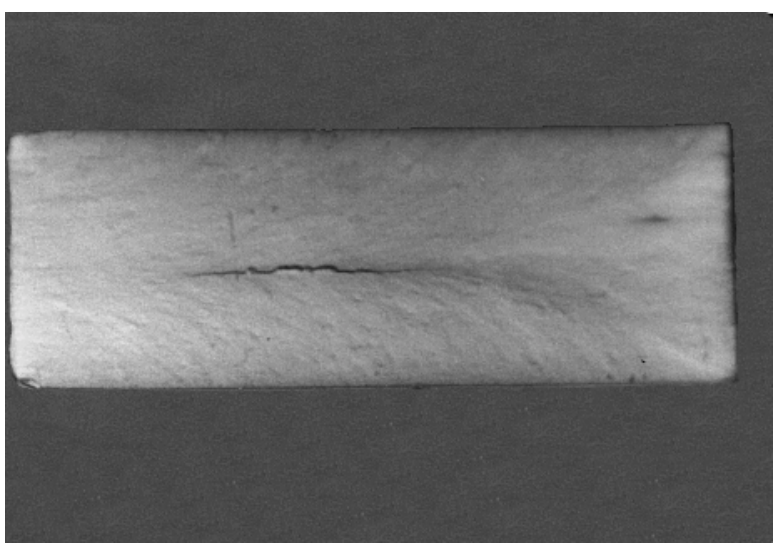

$80^{\circ} \mathrm{C} / 1272 \mathrm{~h}$

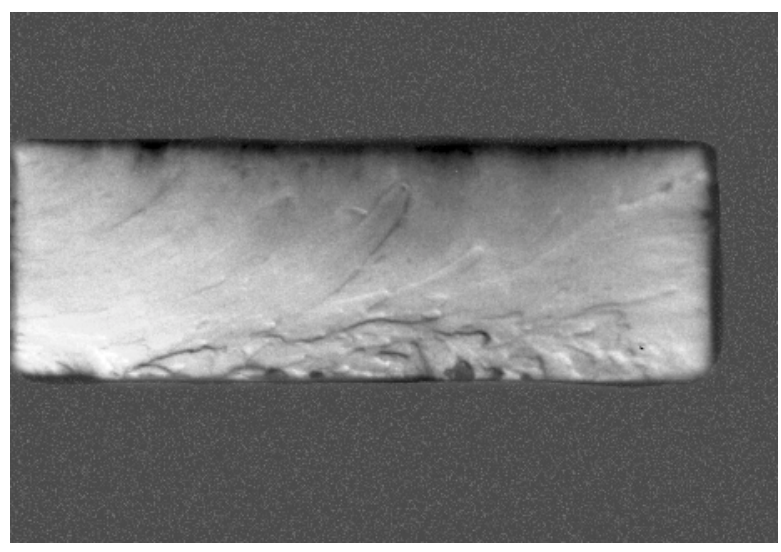

ASTM G24 / 1860 h

Figura 9. Fraturas obtidas nos ensaios de impacto do ABS (aumento de 7 vezes).

foram obtidas as figuras 10 e 11 , correspondentes aos scores e aos loadings, respectivamente. As três primeiras componentes principais contém 93,4\% de informação total dos dados, enquanto as duas primeiras $86,0 \%$.

$\mathrm{Na}$ figura 10 os tempos de envelhecimento do método ASTM G24 estão representados em vermelho, os do método ASTM G53 em azul e do

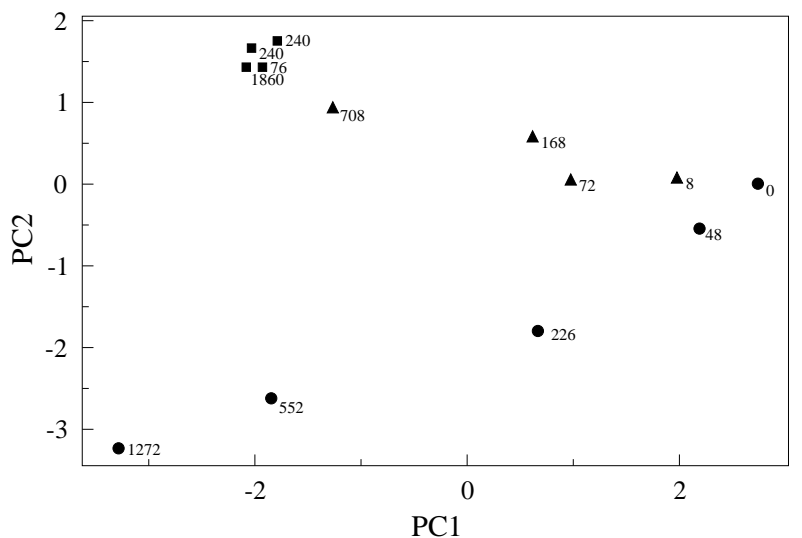

Figura 10. Scores em relação ao método de envelhecimento para o ABS (•: térmico, $\mathbf{~ : ~ A S T M ~ G 5 3 , ~ \bullet : ~ A S T M ~ G 2 4 ) . ~}$ método térmico em verde. Verifica-se que o método térmico causa uma maior variação nas propriedades em relação ao tempo. No método de envelhecimento ASTM G24 as amostras se agrupam, mostrando que não houve muita variação após 240h para os tempos de envelhecimento analisados. A resposta para o método ASTM G53 também foi gradual em relação ao tempo.

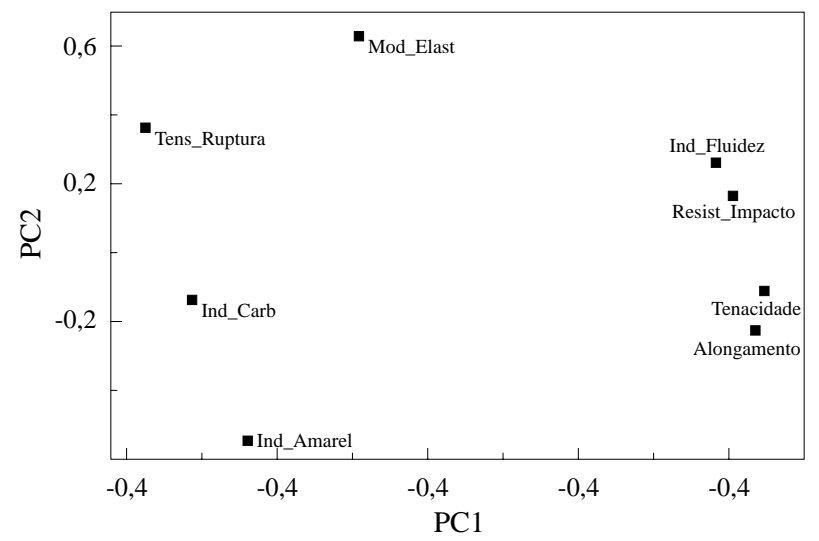

Figura 11. Loadings da propriedades do ABS.ASTM G24). 
$\mathrm{Na}$ figura 11 observa-se que a maior contribuição no envelhecimento térmico é representada pelo aumento gradual dos índices de carbonila e amarelecimento e pela diminuição gradual do alongamento na ruptura, da tenacidade, da resistência ao impacto, da tensão na ruptura, no módulo de elasticidade e índice de fluidez. No método ASTM G53 verifica-se aumento no módulo de elasticidade, da tensão na ruptura, dos índices de carbonila e amarelecimento e diminuição do índice de fluidez, da resistência ao impacto, da tenacidade e do alongamento na ruptura. No método ASTM G24 as amostras envelhecidas se agruparam na região caracterizada por um maior módulo de elasticidade e tensão na ruptura. Verificou-se diminuição no índice de fluidez, na resistência ao impacto, na tenacidade e no alongamento na ruptura.

\section{Conclusão}

Os mecanismos de degradação do ABS são estudados há bastante tempo. A contribuição deste trabalho está na grande variedade de técnicas utilizadas na avaliação de corpos de prova submetidos a três tipos de envelhecimento, que simulam as condições a que acessórios moldados de ABS ficam expostos no interior de um automóvel. Para separar os efeitos de radiação do efeito térmico, foi escolhida a temperatura de $80^{\circ} \mathrm{C}$, por representar uma condição crítica. O método ASTM G53 quando filtrado por vidro reduz o efeito da radiação UV-B que é bastante drástico e possibilita um espectro mais próximo do da luz solar. $\mathrm{O}$ método ASTM G24 é sugerido pela ASTM por si- mular as condições de uma automóvel fechado exposto ao tempo, sujeito tanto à radiação como a altas temperaturas.

Os resultados mostram que cada técnica fornece uma resposta característica em função do polímero e do método de envelhecimento utilizado.

A possibilidade de reutilização deve ser considerada em função das propriedades desejadas.

A análise multivariada permitiu uma visualização dos dados obtidos em cada análise ou técnica de envelhecimento, caracterizando as tendências observadas isoladamente.

\section{Agradecimentos}

À GE Plastics pelo ABS. À FAPESP pela bolsa de pós doutorado (Processo 98/03828-8).

\section{Referências Bibliográficas}

1. Adeniyi, J. B. - Eur. Polym. J., 20, 291-299 (1984).

2. Carter, R. O. \& McCallum, J. B. - Polym. Deg. and Stab., 45, 1-10 (1994).

3. Gardette, J-L.; Mailhot, B. \& Lemaire, J. Polym. Deg. and Stab., 48, 457-470 (1995).

4. Kulich, D. M.; Kelley, P. D. \& Pace, J. E. - Encyclopedia of Polymer Science and Engineering, 2.ed. John Wiley \& Sons Inc., 12: AcrylonitrileButadiene-Styrene Polymers, 388-426 (1986).

5. Malinowski, E. R. - Factor Analysis in Chemistry, 2nd Edition, John Wiley \& Sons Ltd. (1991) 